\title{
Long-Term Isothermal Aging Effects on Carbon Fabric-Reinforced PMR-15 Composites: Compression Strength
}

Kenneth J. Bowles, Gary D. Roberts and John E. Kamvouris

Lewis Research Center

Cleveland, Ohio

Prepared for the

Second Symposium on High Temperature and Environmental Effects on Polymeric Composites

sponsored by the American Society for Testing and Materials Norfolk, Virginia, November 13, 1995 
Trade names or manufacturers' names are used in this report for identification only. This usage does not constitute an official endorsement, either expressed or implied, by the National Aeronautics and Space Administration. 


\title{
LONG-TERM ISOTHERMAL AGING EFFECTS ON CARBON FABRIC-REINFORCED PMR-15 COMPOSITES: COMPRESSION STRENGTH
}

\author{
Kenneth J. Bowles, Gary D. Roberts, and John E. Kamvouris \\ National Aeronautics and Space Administration \\ Lewis Research Center \\ Cleveland, Ohio 44135
}

\begin{abstract}
SUMMARY
A study was conducted to determine the effects of long-term isothermal thermo-oxidative aging on the compressive properties of T-650-35 fabric reinforced PMR-15 composites. The temperatures that were studied were $204,260,288,316$, and $343^{\circ} \mathrm{C}$. Specimens of different geometries were evaluated. Cut edge-to-surface ratios of 0.03 to 0.89 were fabricated and aged. Aging times extended to a period in excess of 15000 hours for the lower temperature runs.

The unaged and aged specimens were tested in compression in accordance with ASTM D-695. Both thin and thick (prism) specimens were tested. Three specimens were tested at each time/temperature/geometry condition. The failure modes appeared to be initiated by fiber kinking with longitudinal, interlaminar splitting.

In general, it appears that the thermo-oxidative degradation of the compression strength of the composite material may occur by both thermal (time-dependent) and oxidative (weight-loss) mechanisms. Both mechanisms appear to be specimen-thickness dependent.
\end{abstract}

\section{INTRODUCTION}

Today, planning is in progress for advanced 21 st century aircraft with greater and faster payload delivery and higher fuel efficiency. Of vital importance in the development of the propulsion systems for these aircraft is the utilization of cost effective materials and manufacturing procedures. The current philosophy in the development of these programs is to utilize the lightweight polymer composites in the higher temperature sections of the new engines. In some cases, the structures may be load bearing. Because of these plans, it is imperative to develop reliable, long-term-durability models so the feasibility of using polyimide-matrix composites as efficient propulsion system materials over the required lifetime of the aircraft can be demonstrated.

Numerous investigations, regarding the thermo-oxidative stability (TOS) of PMR-15 and other hightemperature polyimides, have been conducted and reported [1-7]. A significant amount of this attention has been directed toward edge and geometry effects [1-6], reinforcement fiber influences [3, 4], and modeling of elevated temperature weight loss behavior [7]. This was done as part of an ongoing effort to provide input for use in the prediction of the long-term elevated temperature behavior of structures fabricated from the advanced polymer matrix composite materials. Some of these composite materials are being currently used in aircraft engine secondary structural applications.

In the analysis of numerous TOS results, it has been determined that the specimens lose weight from the different surfaces at different rates. The surfaces of the specimens that were studied were found to undergo two different types of thermo-oxidative transformations during extended periods of elevated temperature aging. The cut edge surfaces experienced significant amounts of crack development and inward growth from the surface. The molded surfaces that are oriented parallel to the ply surfaces suffered from surface cracking, but the cracking did not penetrate as far inward as the cut surface cracks. This was due to the crossply weave of the fabric which, in effect, positioned crack arrestors at each side of the woven tows. It was concluded that the latter surface degradation should bring about changes in the surface-dependent mechanical properties of the aged composites. If the surface degradation controls the changes in mechanical properties during aging, then the properties retention can be related to aging time at a particular temperature for a particular composite system and specimen size. If this

\footnotetext{
- National Research Council-NASA Research Associate at Lewis Research Center.
} 
is not the case, then other mechanisms, along with the surface oxidation, are contributing to the degradation of these materials at elevated temperatures.

The results of a study at the Lewis Research Center [9] showed that aged, unidirectional PMR-15 matrix composites displayed a reduction in the matrix-dependent transverse flexural strength. The magnitude of the decrease increased with aging time. Also in this study, and in another study [10], it was observed that mechanical properties that are not sensitive to surface properties, such as in plane shear strength, do not exhibit significant property degradation due to exposure to the hostile environment and aging times up to $1000 \mathrm{hr}$ at $316^{\circ} \mathrm{C}$.

The purpose of the study described herein was to confirm the role of the oxidizing surface layer in mechanical properties degradation during elevated temperature aging. It was also initiated to point out possible causes, evolving from the formation and growth of this layer over extended periods of times approaching $20000 \mathrm{hr}$, for the degradation of properties. The compression properties were chosen for study because they play a significant role in impact, delamination, and other types of damage failures caused by out of plane forces.

\section{MATERIALS}

The materials used in this study were PMR- 15 polyimide composites reinforced with T- $650-35,24$ by 23 , 8-harness satin carbon fiber fabric. The material was supplied by ICI Fiberite. The composites were fabricated by autoclave techniques at $316^{\circ} \mathrm{C}$. The molded surfaces exhibited a roughened appearance from the bleeder cloth that was used. The cure was followed by a free-standing post cure at $316^{\circ} \mathrm{C}$ in an air-circulating oven for $16 \mathrm{hr}$. All processing was done at the General Electric Aircraft Engine Plant in Evendale, Ohio.

The specimen designations and nominal dimensions are presented in Table 1 and Figure 1 . The dimensions were selected to provide specimens with different molded surface (resin rich areas adjacent to the vacuum bag containment materials) to cut surface area ratios. The percentage of cut surface areas varied from 2.7 to 89 percent of the total surface area. The numeral designations of the specimens in Table 1 reflect the nominal percent cut edge areas. The material in this study was found to have void contents less than $2 \mathrm{vol} \%$ and to be free from delaminations. The fiber volume fractions ranged from 0.55 to 0.59 . A typical photomicrograph of the material prior to aging is shown in Figure 2. Some resin rich areas are present between the tows.

\section{Test Procedures}

The composite specimens were aged in air-circulating ovens. The ovens maintained an air flow rate of $100 \mathrm{~cm}^{3} / \mathrm{min}$. The temperatures that were studied were $204,260,288,316$, and $343^{\circ} \mathrm{C}$. The specimens were removed from the ovens at regular intervals and placed in a desiccator where they cooled to room temperature. The specimens were not removed from the desiccator until they were ready to be weighed. The weights were recorded and the specimens were returned to the ovens. At scheduled times, selected specimens were permanently removed from the ovens for various tests including compression tests.

The glass transition temperatures were measured utilizing dynamic mechanical analysis. Measurements were made with rectangular pieces, using a Rheometrics RMS- 800 rheological spectrometer. The test pieces were stressed in torsion across the specimen widths. The test pieces measured $60 \mathrm{~mm}$ in length, $10 \mathrm{~mm}$ in width, and ranged in thickness from 1.3 to $7.5 \mathrm{~mm}$. They were mounted in grips that were separated to give a gage length of $45 \mathrm{~mm}$. The two components of the complex shear modulus were measured as a function of temperature. A frequency of $1 \mathrm{~Hz}$ with an amplitude of 0.1 percent strain and a heating rate of $5{ }^{\circ} \mathrm{C} / \mathrm{min}$ were used. All specimens were dried in an air-circulating oven at $125^{\circ} \mathrm{C}$ for $24 \mathrm{hr}$ before they were tested. This was a sufficient amount of time to reduce the moisture to very low values [11]. The glass transition temperatures were determined by measuring the intersection of the two tangents to the $G^{\prime}$ curve where it changes slope. This is illustrated in Figure 3.

The compression tests were done at the Cincinnati Testing Laboratories in Forest Park, Ohio. There were two types of compression tests that were performed in accordance with ASTM D-695M. One was the test for specimens of thickness less than $3 \mathrm{~mm}$., and the second was specified for specimens with thickness greater than 3 $\mathrm{mm}$. The composites that were tested in accordance with the thin specimen specifications were the T-3, T-5, and T-12 plates. The T-50 composite was tested as described in ASTM D-695M for thick specimens. The crosshead speed was $1.2 \mathrm{~mm} / \mathrm{min}$. Strain measurements were made using an extensometer. No end tabs were used. All 
specimens were conditioned at $125^{\circ} \mathrm{C}$ for $16 \mathrm{hr}$ prior to testing. The tests were run at $23.3^{\circ} \mathrm{C}$ and a relative humidity of 50 percent.

The fiber contents of the composites were measured by acid digestion as described in ASTM D-3171. The void volume was calculated as the difference between the specific volume of a composite specimen, measured using the immersion technique as specified in ASTM D-792, and the theoretical specific volume calculated from the acid digestion results. The differences were divided by the measured specific volume and multiplied by 100 to give the void volume in percentage. The densities of the polymer and the fiber were taken to be 1.32 and $1.78 \mathrm{~g} / \mathrm{cm}^{3}$, respectively.

\section{RESULTS}

\section{Dynamic Mechanical Analysis}

The $T_{G} S$ of the specimens that were aged at different temperatures for different durations were measured and the data are presented in Table 2. The types of specimens that were tested were the $T-3, T-5$, and $T-12$ plates, which contained over 90 percent of molded exposed surfaces.

The $T_{G}$ measurements in Table 2 present values only for aged $T-5$ specimens. They indicate that at temperatures below $260^{\circ} \mathrm{C}$, the $\mathrm{T}_{\mathrm{G}}$ is dependent on the temperature of aging and not the period of aging. This is probably due to the large differences between the aging temperatures and the $316^{\circ} \mathrm{C} 16-\mathrm{hr}$ post cure treatment temperature. Most chemical changes that would occur over an extended time period at the lower temperatures occurred quickly at the higher post cure temperature. At temperatures above $260^{\circ} \mathrm{C}$ there are differences due to both aging times and temperatures.

\section{COMPRESSION STRENGTH}

\section{Effects of Aging on Compression Strength}

Compression strength values for the T-5 specimens are compared as a function of both temperature and time in Figures 4 and 5. The data group differently for the two independent variables. The compression strength data for the specimens that were aged at the higher temperatures appear to be represented by a single curve when they are plotted against percent weight loss. By regression analysis, the data for the T-5 specimens that were aged at 260 , 288,316 , and $334^{\circ} \mathrm{C}$ were fitted to an exponential curve with a slope of $-10.3 \times 10^{-2}$ and an intercept of 100.9 (in ksi units). The coefficient of variation, $\mathrm{R}^{2}$, value is 0.970 . This indicates good correlation between the strength and weight loss. The intercept in MPa units is 695.7. The slope and $\mathrm{R}^{2}$ remain the same. The resulting equation is

$$
\text { Ln } S_{c}=4.614-10.259 \times 10^{-2} \mathrm{w}
$$

where $\mathrm{S}_{\mathrm{c}}$ is the compression strength in $\mathrm{MPa}$ and $\mathrm{w}$ is the weight loss in percent. When the strengths are plotted against aging time, the materials aged at 204 and $260^{\circ} \mathrm{C}$ produce data that form a common curve with an exponential slope of $-6.480 \times 10^{-5}$, an intercept of 111.57 in ksi units and an $\mathrm{R}^{2}$ value of 0.926 . The intercept is 769.26 in MPa units. The resulting mathematical relationship is

$$
\text { Ln } S_{c}=4.710-6.480 \times 10^{-5} t
$$

for the same strength units as in (1) and $t$ is aging time in hours. At these two temperatures, the weight loss does not control the degradation of the compression strength since the weight loss at $204{ }^{\circ} \mathrm{C}$ is about one-tenth of that at $260^{\circ} \mathrm{C}$ as shown in Figure 4. It appears that there are significant differences in relationships between the data sets depending on the exposure temperatures. These data indicate that weight loss behavior cannot be used to evaluate structural integrity of PMR-15 composite materials over temperature levels below $260^{\circ} \mathrm{C}$. The effect of the formation of microcracks may be a factor which has a great influence on the mechanical property degradation. 
However, since the concentration of microcracks in the material aged at $204^{\circ} \mathrm{C}$ is less than that of the material aged at $260^{\circ} \mathrm{C}$, and the compression strengths are very close, it is not the single factor involved.

Figures 6,7 , and 8 show how the effect of increasing specimen thickness in decreasing compression strengths for aged specimens. The data in Figure 6 are from T-12 specimens that are thicker than the T-5 material. It is evident that the time to reduce the compression strength by 50 percent for the T-5 material aging at $260^{\circ} \mathrm{C}$ is about $12000 \mathrm{hr}$ (Fig. 5). The time for strength reduction to the same level for the thicker T-12 specimens appears to be greater than $20000 \mathrm{hr}$. This is a significant increase.

The contrast between specimen thicknesses and also between test methods is shown graphically in Figures 7 and 8 . The data at 0 time (unaged specimens) shown in Figure 7 for the T-3, T-5, and T-12 composites do not show statistically different strength values due to the thickness differences. As the aging time at $316^{\circ} \mathrm{C}$ increases past 1 percent, the strength values start separating. The thinnest (T-3) specimens lose their strength the fastest. After about 2 percent weight loss, the slopes of the three curves appear to be parallel which indicates the same rate of loss of strength. The differences in the aged T-3, T-5, and T-12 compression strengths are probably due to the damage incurred during aging and not the thickness. These specimens have 4,8 , and 20 plies, respectively, through the thickness. From measurements using optical microscopy methods to measure surface layer thicknesses, the changes in residual strengths appear to match up mathematically with the differences in effective thickness. For example, if one calculates the measured compression strength for each size specimen by assuming the outer oxidized layer is not strong enough to sustain the full test failure load, and the failure load is carried only by the cross sectional area minus the area of the two oxidized layers, the calculated surface layer thicknesses are consistent between the three different samples. This will be studied further.

In Figure 8, T-5 and T-50 compression strength data are plotted against percent weight loss. The data were measured from specimens aged at all temperatures except $204^{\circ} \mathrm{C}$. When the specimen thickness is increased to that of the T-50 specimen $(1.3 \mathrm{~cm})$, then the measured unaged specimen test data are about 90 percent of the values for the thinner specimens. Again the two curves are similar, but this time neither specimen seems to lose strength at a faster rate than the other after the initial 1 percent of weight loss has taken place. It is apparent that the unaged material data shown in Figure 7 are not affected by thickness differences as they are in Figure 8 . The differences observed in Figure 7 are therefore thermal and oxidative effects.

\section{Compression Modulus}

Figures 9 and 10 show the measured moduli of some of the specimens that were aged isothermally in this study. Initially, the moduli increase slightly during the first $4000 \mathrm{hr}$. The time for maximum modulus increase decreases with increasing aging temperature. The increase is attributed to an increase in crosslinking at the aging temperature. Again, the composites that were aged at the lower temperatures show almost identical relationships with aging time. Only the specimens that were aged at 316 and $343^{\circ} \mathrm{C}$ lose their moduli at a faster rate than the other specimens. One interesting observation is that the specimens that were aged at $204^{\circ} \mathrm{C}$ show no increase in moduli similar to the other two lower temperature specimens. In contrast, when the percent weight loss is the independent variable as in Figure 10, only the material aged at $204^{\circ} \mathrm{C}$ falls outside of the band of data produced by the tests of the material aged at the higher temperatures.

Figure 11 presents data measured using T-12 specimens. It is obvious that the thicker specimens retain their modulus longer than the thinner T-5 specimens. The moduli are definitely thickness-dependent for the aged material.

The moduli were calculated from the formula, $\mathrm{E}_{\mathrm{C}}=\left(\mathrm{P}_{1500}-\mathrm{P}_{500}\right) / .001 \mathrm{bd} . \mathrm{E}_{\mathrm{C}}=$ modulus of elasticity. $\mathrm{P}_{1500}=$ load at 1500 microstrain. $\mathrm{P}_{500}=$ load at 500 microstrain. $\mathrm{b}=$ specimen width. $\mathrm{d}=$ specimen thickness. The microstrains were measured with the extensometer.

\section{Microscopy}

Figures 12 to 15 show comparisons between two specimens aged at 288 and $316^{\circ} \mathrm{C}$ and two that were aged at 204 and $260^{\circ} \mathrm{C}$. Figures 12 and 13 show the composites that were aged at $316^{\circ} \mathrm{C}$ for 500 and $1000 \mathrm{hr}$ with weight losses of 11.3 and 3.6 percent, respectively. These pictures show distinct surface layers of damage with the 
$1000 \mathrm{hr}$ of aging producing more microcracking than the shorter duration of aging. The lower temperature aging for $10000 \mathrm{hr}$ produced weight losses of 0.40 and 3.9 percent, respectively. In contrast, Figures 14 and 15 show that damage from the thermal exposures is not confined to the surfaces. In fact, no distinct surface layer is observed in either Figure. The entire cross sections of both composites are filled with evenly distributed intraply cracks, some of which develop into delaminations as shown in Figure 15. The concentrations of the cracks in the two figures are not the same. The materials aged at $204^{\circ} \mathrm{C}$ contain less cracks. Figures 13 to 15 also show backscattering from oxygen atoms in the specimens as produced by Scanning Electron Microscope Backscattering Electrons (SEM-BSE). The extent of damage becomes clearer due to these pictures. The light areas are sites where the oxygen atoms are highly concentrated. The oxygen is only concentrated around the cracks at the surfaces in Figures 12 and 13. It is evident that an increase in aging time, as observed when comparing these two figures, causes not only an increase in oxygen concentration around the surface cracks, but it also causes a significant increase in surface damage by cracking. The SEM-BSE pictures in Figures 14 and 15 show the damage produced in the composites aged at the two lowest temperatures. It is evident that the oxygen pickup is not concentrated exclusively at the surfaces of the material. Oxygen has penetrated to areas within the inner composite material. It is significant that the oxygen is not concentrated around the internal cracks that are distributed throughout these specimens. Oxygen penetration from the outside probably does not occur through a network of these cracks. It does appear that the areas of oxygen concentration follow the tows that run parallel to the plane of the polished surface. Since no obvious horizontal cracks are evident in these photographs [14 and 15], it might be that oxygen diffusion is a significant factor in the formation of damage. The damage which has occurred does involve the formation of internal cracks, delaminations, and the reaction of the matrix with oxygen.

\section{Failure Modes}

Figures 16 to 18 reveal failure modes for specimens that were aged in this study. The larger T-50 specimens failed by a combination of fiber kinking and delamination. The delaminations appear to be formed by expansion due to the formation of a wedge at one end of the thick specimen (Fig. 16). The movement of the wedge inward toward the middle of the length of the specimen forces the outer surfaces of the specimen to separate from the specimen. The thinner T-12 specimens failed as shown in Figure 17. The failure is similar to that for the T-50 specimen. However, it occurs in the gage section and not at the end.

As the aging time increases at a particular temperature the failure appears to occur by "brooming" at one end of the specimen (Fig. 18). This suggests that the transverse strength has deteriorated significantly. The end failures occurred in the T-12 specimens that were exposed at the lower temperatures for times of $15830 \mathrm{hr}$ but the specimens aged for $17720 \mathrm{hr}$ failed in the gage sections. The T-3 specimen failed at the ends after $1510 \mathrm{hr}$ at $316^{\circ} \mathrm{C}$. These data are included in the strength plot shown in Figure 6 for the T-12 specimens. The strengths are significantly lower than the values for gage area failures.

\section{DISCUSSION AND CONCLUSIONS}

The results of this study indicate that thermo-oxidative stability at elevated temperature by itself is not a valid measure of long-term durability of polymer-matrix composites. This was evidenced in the data from the aging tests conducted at 204 and $260^{\circ} \mathrm{C}$. Property measurements must be made to properly assess the potential of polymer-matrix composites. Results similar to this were published in Reference 13 which addressed the use of epoxy-matrix composites as long-term materials of construction for aircraft engine components. Mathematical models which are developed to predict long-term mechanical property durability must include terms that describe thickness, weight loss, and microcrack density effects. These results also indicate that attempts to predict long-term durability of mechanical properties of the polyimide composite from accelerated testing or extrapolation of short term aging test data may be unreliable even when extrapolating downward in temperature.

Two more important conclusions can be drawn from the results of the work described herein. The first is that the compression properties retention is dependent not only on the weight loss but also on the aging time over the temperature range that was studied. This is observed only for specimens of the same geometric size. The second conclusion is that specimen thickness has a significant affect at all temperatures. Any modeling that is to be 
developed to describe the durability of these composites should include both of these effects. The data indicate a strong relationship between these two independent variables when regression analyses are performed. The most effective mathematical relationship is an exponential one.

A cursory examination of Figures 4 and 5 may lead one to believe that there may be at least two different mechanisms involved in the thermo-oxidative degradation of the PMR-15 composite laminates over the temperature range that was studied. At lower temperatures, the weight loss data indicate that the oxidativedegradation rate is very low while the compression strength degrades significantly more than at identical weight loss levels at higher temperatures. This is contrary to the initial premise that the surface degradation may control mechanical properties changes. It might be concluded that the degradation which diminishes the compression strength at the lower temperatures affects the bulk of the composites much more than the surfaces. At the higher temperatures, the loss in compression strength is shown to be directly related to the percent weight loss for the same thickness of specimens. If the weight loss is assumed to be concentrated in the oxidizing surface layers, then the initial assumption holds true and the weight loss can be related to the surface layer thickness at these temperatures. Earlier work reported in Reference 3 indicates a change in oxidative degradation activation energy over the temperature range from 260 to $343{ }^{\circ} \mathrm{C}$. This suggests that there is a change in mechanisms over the temperature range that was studied.

Pictures showing oxygen distribution throughout the specimens aged at the lower temperatures do not indicate a uniform concentration of oxygen throughout the internal volume. The oxygen is observed to concentrate along the lateral surfaces of some fiber tows and not around the internal cracks that have developed during the aging. When one compares Figures 14 and 15, the damage in the specimen aged at $204{ }^{\circ} \mathrm{C}$ is much less than the damage in the specimen aged at $260^{\circ} \mathrm{C}$. However, the two specimens have the same compression strengths and moduli. Because of this, it appears that the internal cracking is not the dominant factor in the reduction of properties.

The variation of compression strength with specimen thickness at the lower temperatures suggests that a chemical change does not occur evenly throughout the entire volume of the composite material. The change in material probably advances inward from the surfaces by diffusion along the fiber tows as the aging time progresses. The initiation and growth of intraply cracks might be due to a density change in the matrix material caused by chemical changes that result in matrix shrinkage. This was reported in Reference 8 . The difference in crack density within the specimens aged at 204 and $260^{\circ} \mathrm{C}$ suggest that any chemical change that may be taking place proceed at different rates and are further from completion in the former specimens. During the analysis of thermal cycling test specimens, it has been observed that microcracks develop in polymer matrix composites from the outer surfaces inward and then they multiply. This type of crack initiation could also contribute to the low-temperature property degradation observed in this study.

If a strength loss of 50 percent is arbitrarily set, the data indicate that composite thickness over $0.66 \mathrm{~cm}$ may allow structures to sustain design loads for times over $30000 \mathrm{hr}$. The upper thickness limit has not been established in this study, but the potential for thick structure durability appears to be there. The data also suggest that materials having a thickness less than $0.66 \mathrm{~cm}$ in all probability cannot survive temperatures of $316^{\circ} \mathrm{C}$ and possibly $288^{\circ} \mathrm{C}$ for the $30000 \mathrm{hr}$.

\section{REFERENCES}

[1] Bowles, K.J. and Meyers, A., Proceedings of 31st SAMPE International Symposium and Exhibition, J.L. Bauer and R. Dunaetz, Eds. SAMPE, Covina CA, 1986, pp. 1285-1299.

[2] Bowles, K.J. and Nowak, G., Journal of Composite Materials, vol. 22, 1988, p. 966.

[3] Bowles, K.J., SAMPE Quarterly, vol. 21, 1990, p. 6.

[4] Magendie, F.J., "Thermal Stability of Ceramic AND carbon Fiber Reinforced Bismaleimide Matrix Composites," Master's Thesis, Dept. of Chem. Eng., Univ. of Washington, Seattle, 1990.

[5] Nan, D.J. and Sefaris, J.C., SAMPE Quarterly, vol. 24, 1992, p. 10.

[6] Bowles, K.J. and Kamvouris, J.E., Journal of Advanced Materials, vol. 26, 1994, p. 2.

[7] McManus, H., "Coupled Materials and Mechanics Analyses of Durability Tests for High Temperature Polymer Matrix Composites," Second Symposium on High Temperature and Environmental Effects on Polymer Composites, ASTM, Norfolk VA, Nov. 13, 1995.

[8] Bowles, K.J., Jayne, D., and Leonhardt, T.A., SAMPE Quarterly, vol. 24, 1993, p. 2. 
[9] Camponeschi, E.T. Jr.,"Compression Response of Thick-Section Composite Materials," Ph. D. Thesis, Dept. of Mech. Eng., University of Delaware, 1990.

[10] Madhukar, M.S., Bowles, K.J., and Papodopoulos, D.S., Proceedings of the First International Conference on Composites Engineering, David Hui, Ed., New Orleans, LA, 1994.

[11] Roberts, G.D., Malarik, D.C., and Robaidek, J.O., Proceedings of the Eighth International Conference on Composite Materials, S.W. Tsai and G.S. Springer, Eds. SAMPE, Covina, CA, pp. 12-H-1 to 12-H-10.

[12] T.K. Tsotsis, Journal of Composite Materials, vol. 29, 1995, p. 410.

TABLE 1.-T-650-35 graphite/PMR-15 composite dimensional data.

\begin{tabular}{|l|c|c|c|c|}
\hline Specimen & $\begin{array}{c}\text { Length, } \\
\mathrm{cm}\end{array}$ & $\begin{array}{c}\text { Width, } \\
\mathrm{cm}\end{array}$ & $\begin{array}{c}\text { Thickness, } \\
\mathrm{cm}\end{array}$ & $\begin{array}{c}\text { Edge, } \\
\%\end{array}$ \\
\hline T-3 & 8.94 & 10.83 & 0.13 & 2.6 \\
$\mathrm{~T}-5$ & 8.94 & 10.83 & 0.25 & 5.4 \\
$\mathrm{~T}-12$ & 8.94 & 10.83 & 0.75 & 11.9 \\
$\mathrm{~T}-50$ & 4.51 & 4.51 & 1.30 & 50.3 \\
\hline
\end{tabular}

TABLE 2-Glass transition temperatures of T-5 Specimens at different times and temperatures.

\begin{tabular}{|r|c|c|c|c|c|}
\hline \multirow{2}{*}{$\begin{array}{c}\text { Time, } \\
\text { hr }\end{array}$} & \multicolumn{5}{|c|}{ Temperature, ${ }^{\circ} \mathrm{C}$} \\
\cline { 2 - 6 } & 'RT & 204 & 260 & 288 & 316 \\
\hline 0 & 330 & & & & \\
0 & 342 & & & & \\
0 & 341 & & & & \\
500 & & & & & 358 \\
1000 & & & & 349 & 364 \\
2000 & & 328 & 330 & 352 & 391 \\
5000 & & 323 & & 346 & \\
10000 & & 322 & 349.5 & & \\
\hline
\end{tabular}



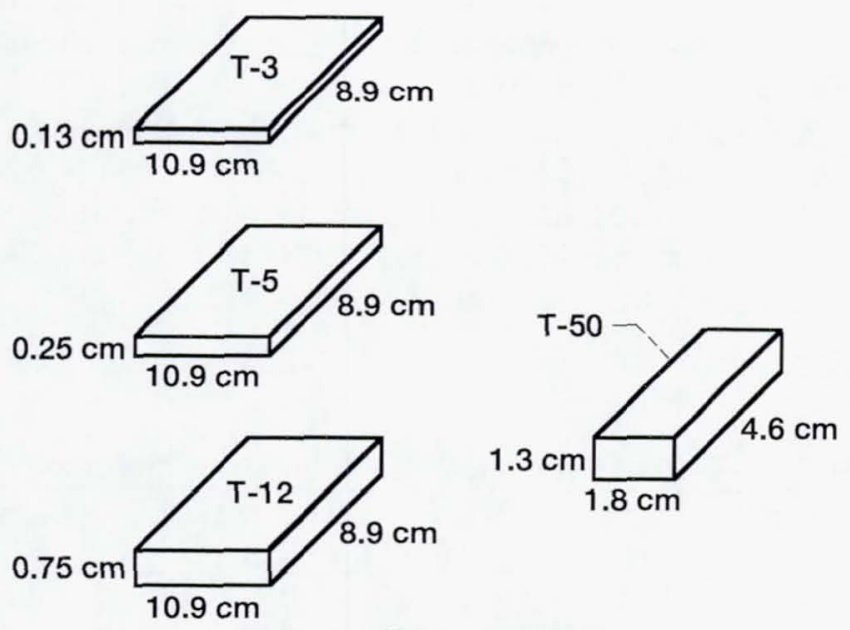

Figure 1.-Test specimens.

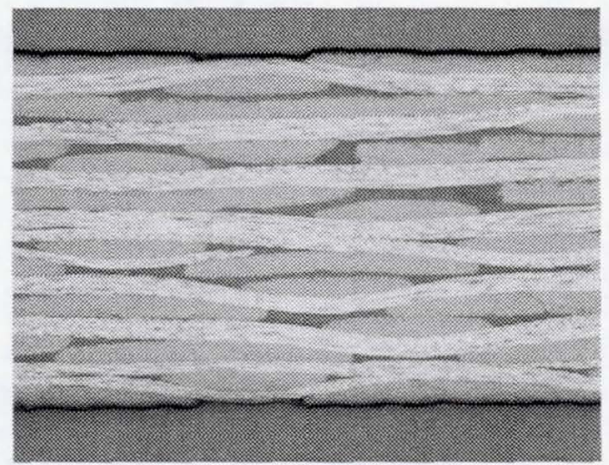

Figure 2.-Unaged T650-35/PMR-15 fabric reinforced composite.

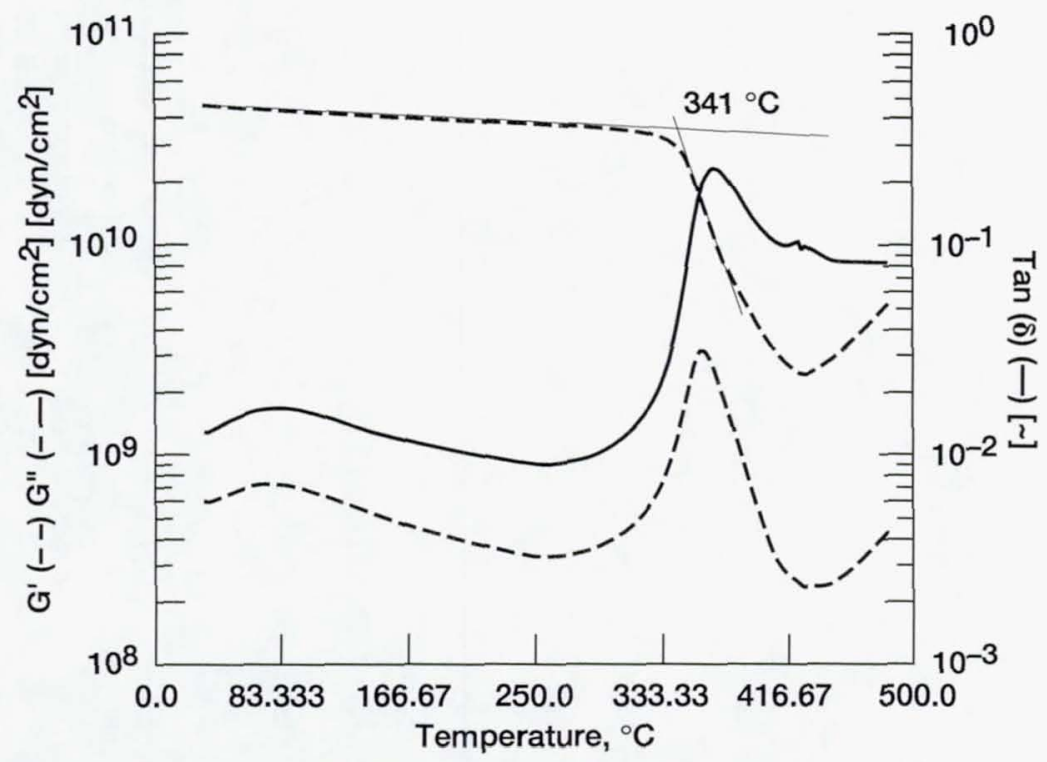

Figure 3.-Dynamic mechanical analysis data from T-5 specimen with no ageing. 


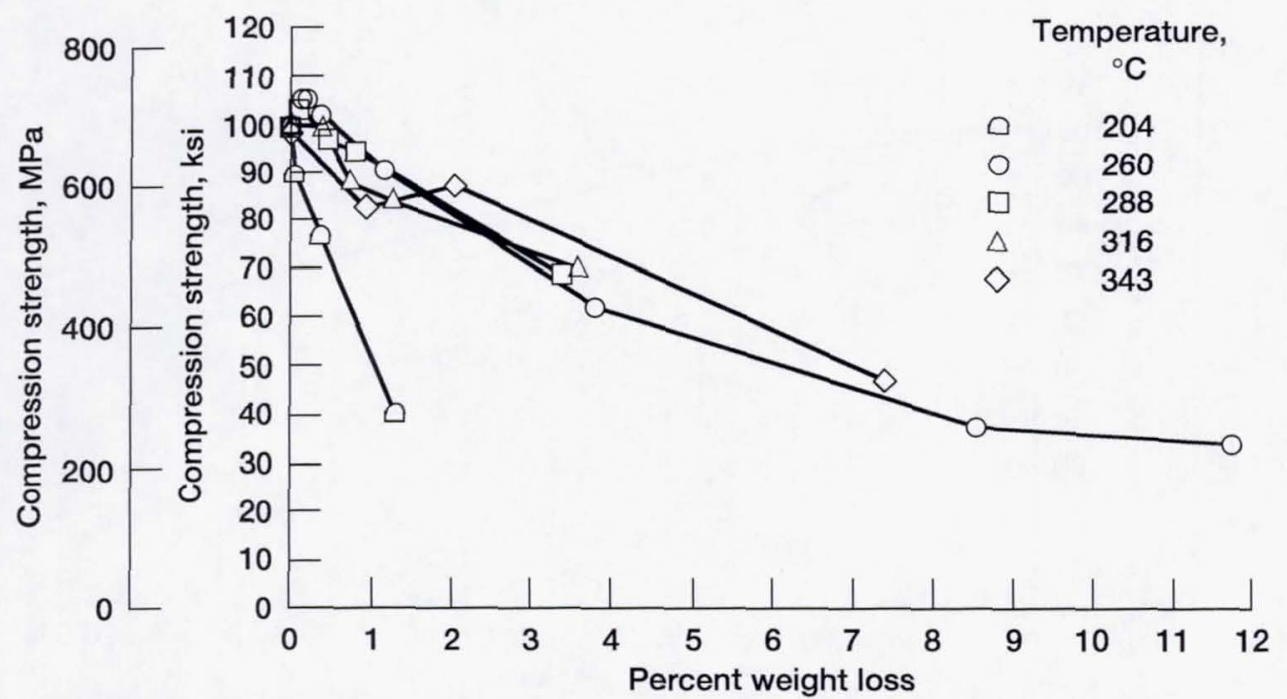

Figure 4.-Compression strength of T650-35/PMR-15 T-5 composite specimens as a function of percent weight loss at various temperatures

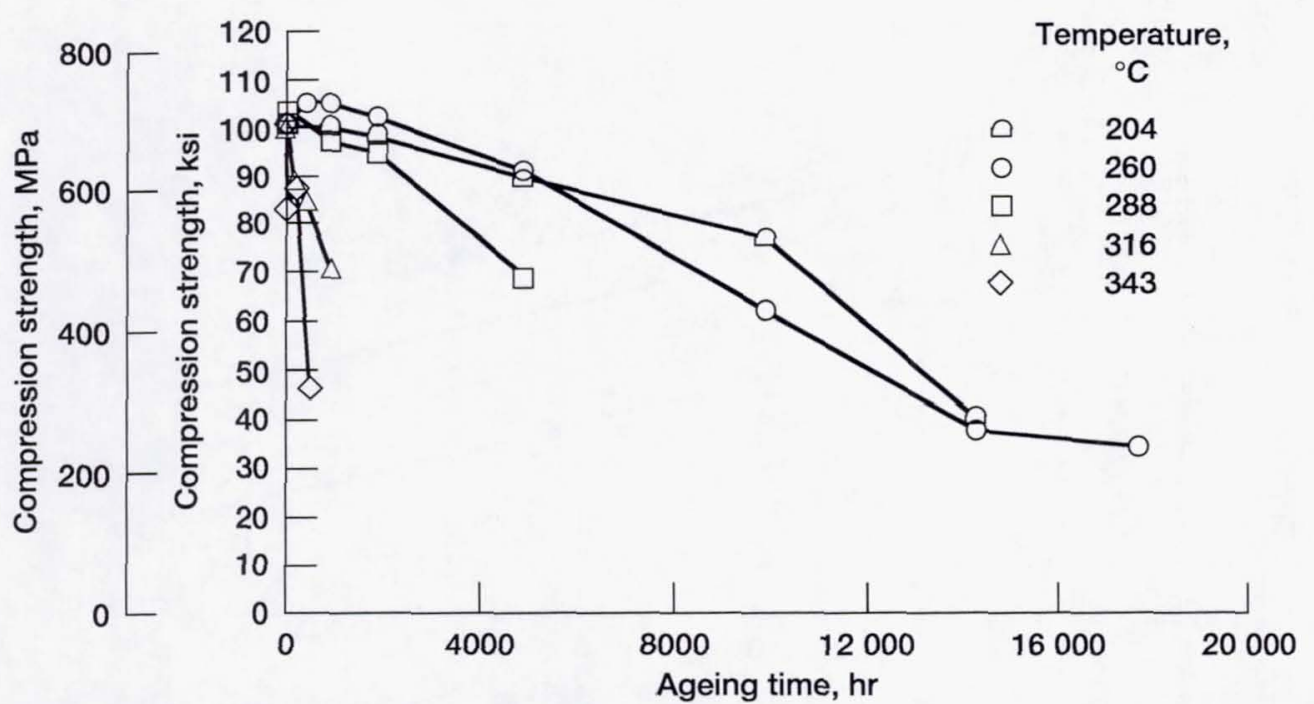

Figure 5.-Compression strength of T650-35/PMR-15 T-5 composite specimens as a function of ageing time at various temperatures. 


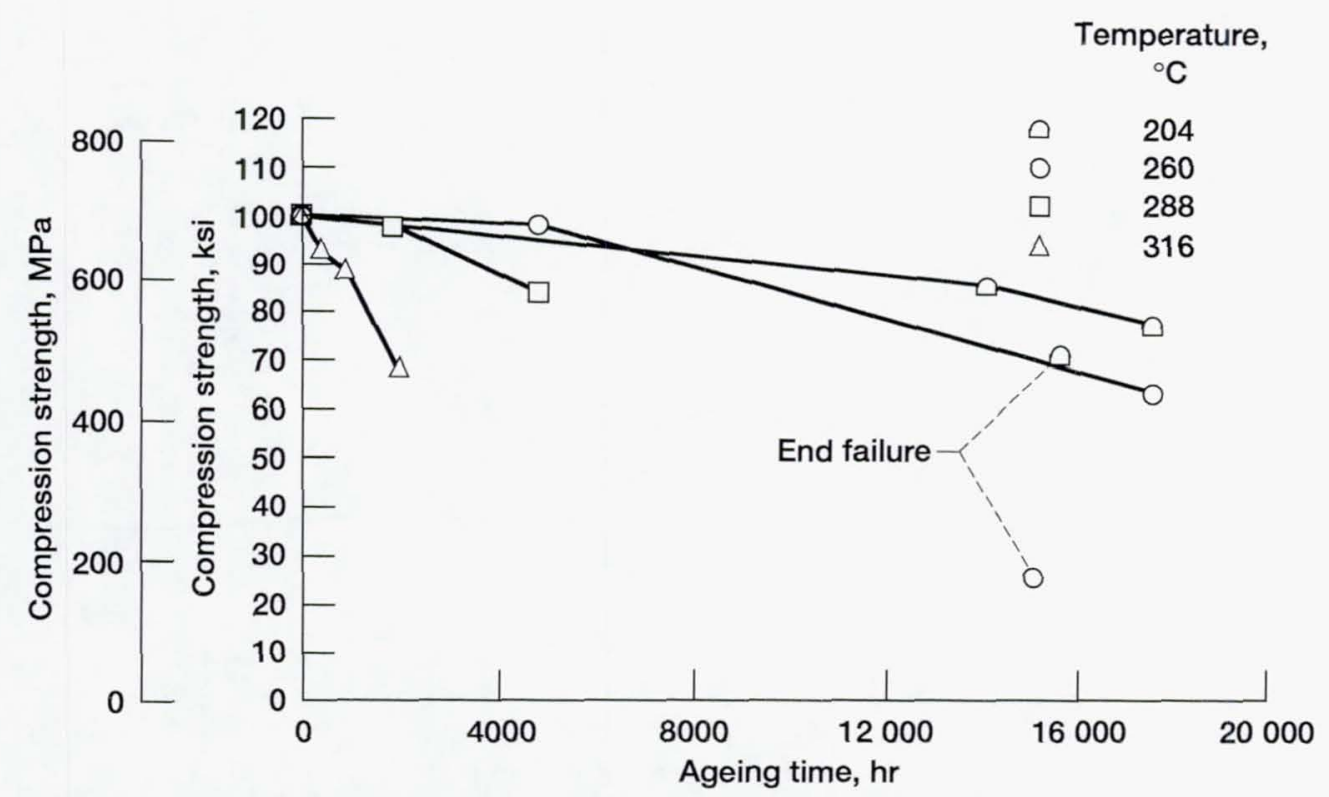

Figure 6.-Compression strength of T650-35/PMR-15 T-12 composite specimens as a function of ageing time at various temperatures.

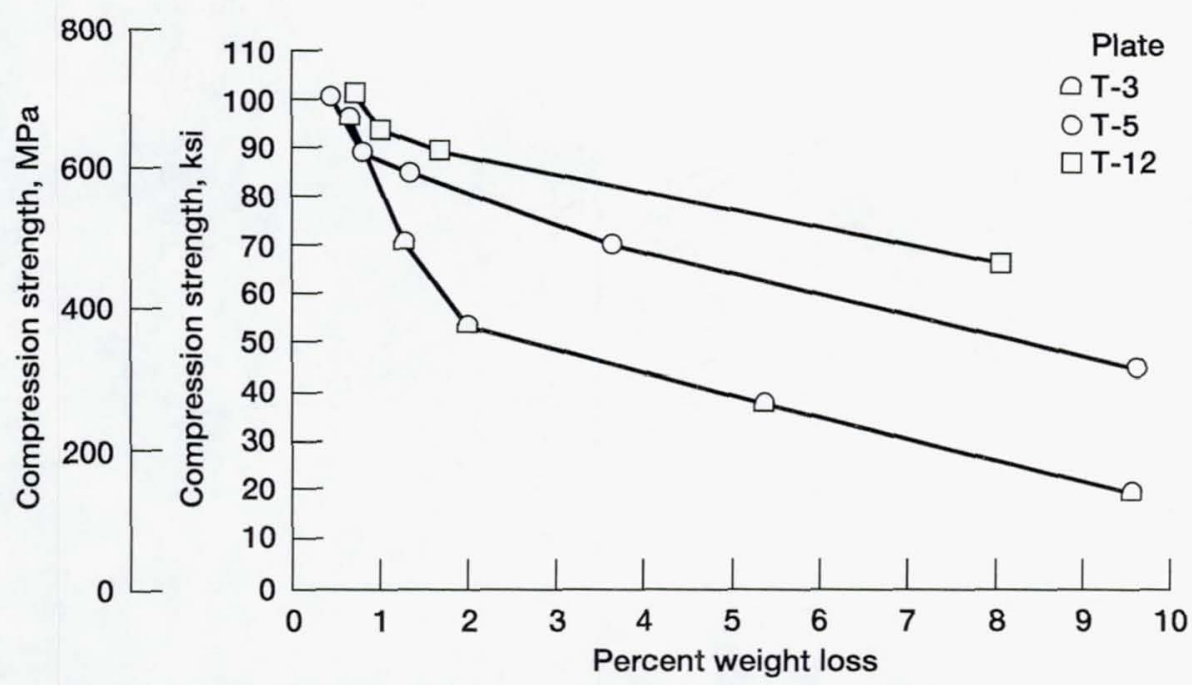

Figure 7.-Compression strength of T650-35 fabric/PMR-15 composites of different thicknesses after ageing in air $316^{\circ} \mathrm{C}$. 


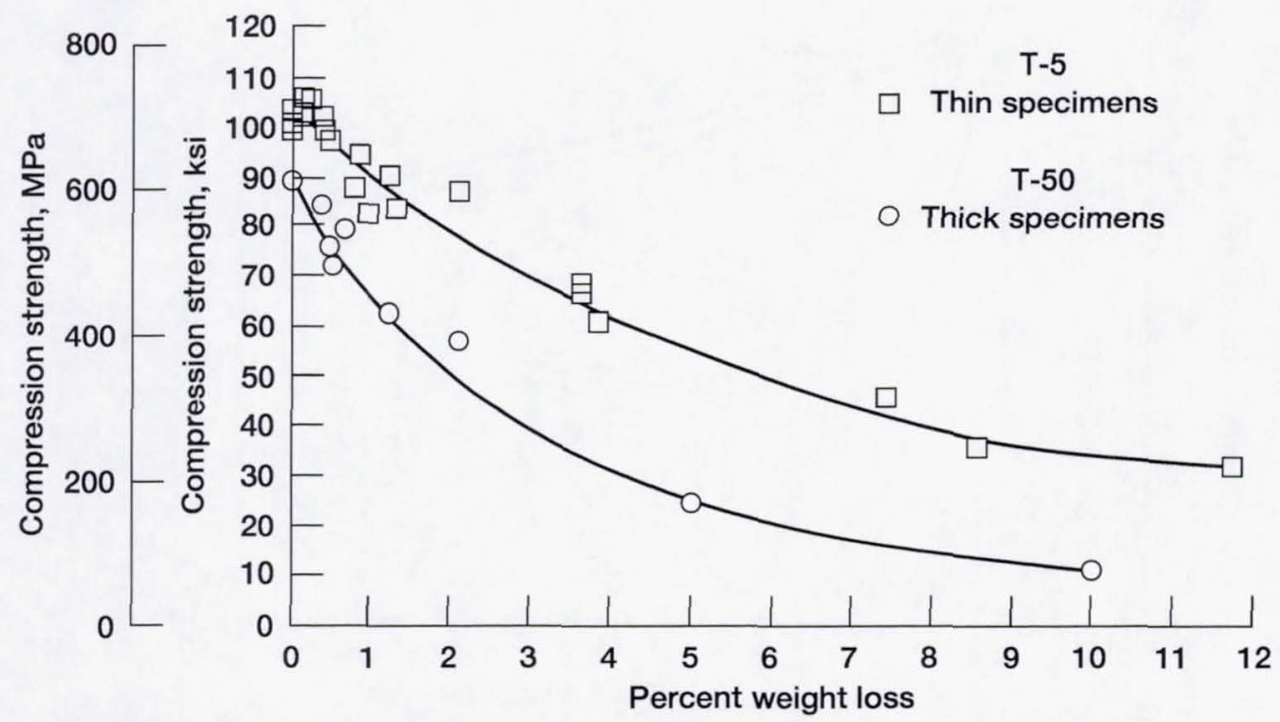

Figure 8.-Compression strength of T650-35/PMR-15 composites as a function of percent weight loss.

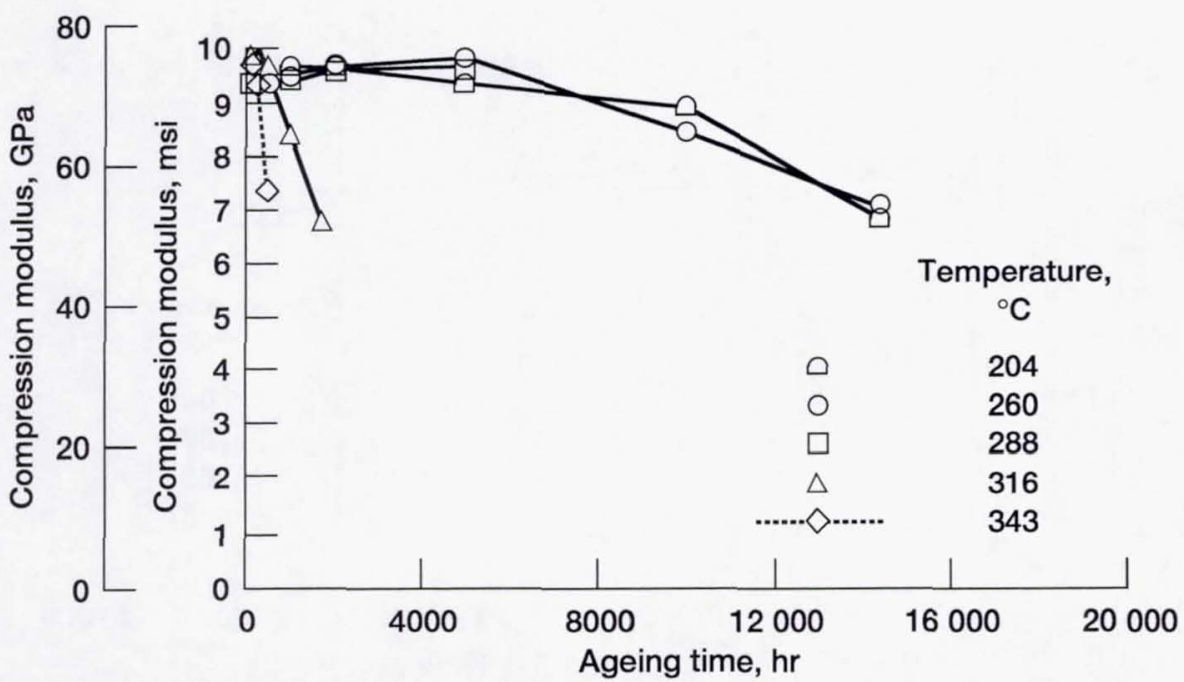

Figure 9.-T-650-35/PMR-15 composite compression modulus degradation as a function of both ageing time and ageing temperature. All specimens are T-5 size. 


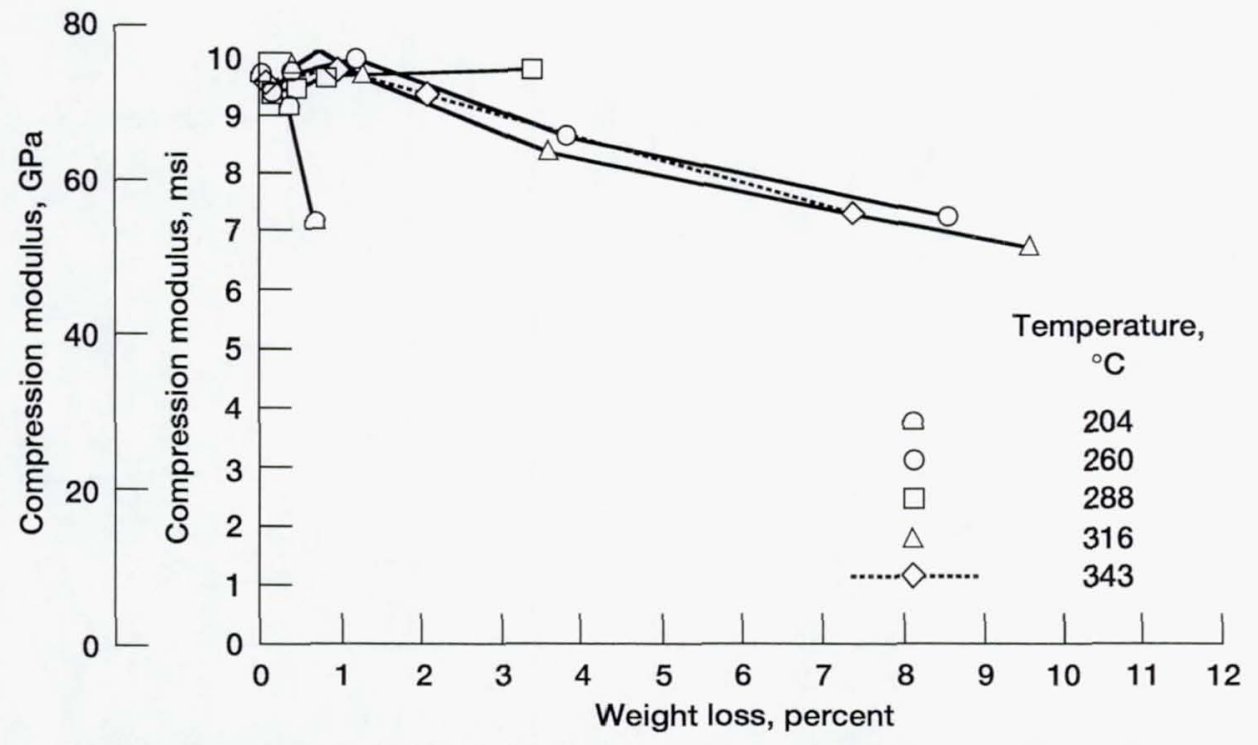

Figure 10.-T650-35/PMR-15 composite compression modulus as a function of both ageing temperature and weight loss. All specimens are $\mathrm{T}-5$ size.

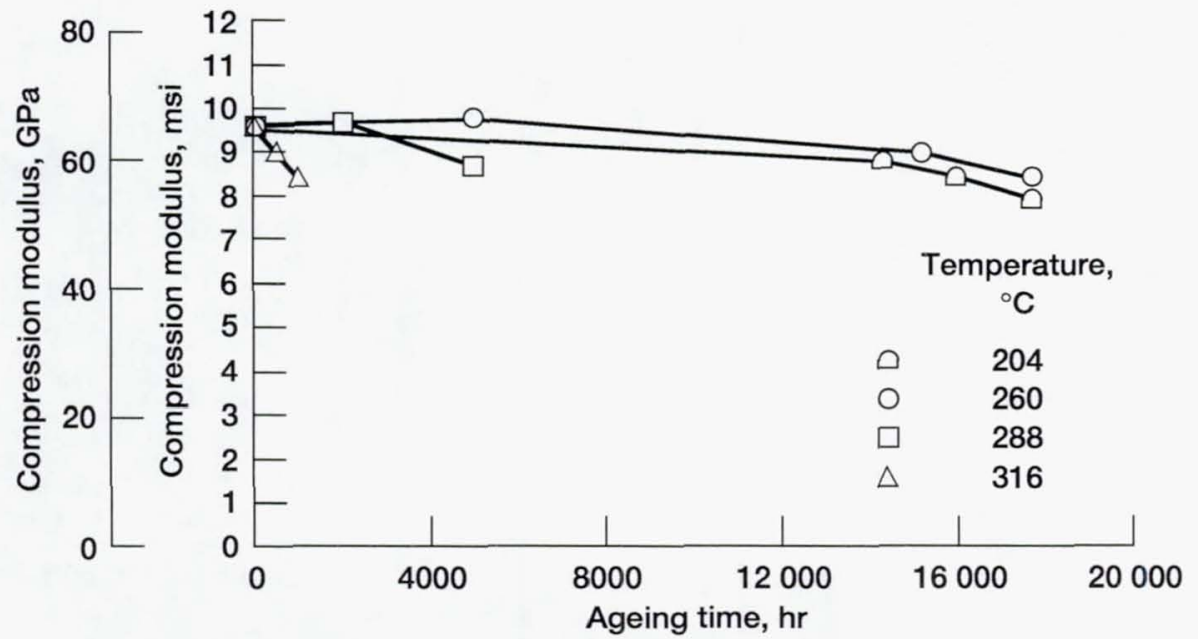

Figure 11.-Compression modulus of T650-35/PMR-15 T-12 specimens as a function of ageing time at various temperatures. 

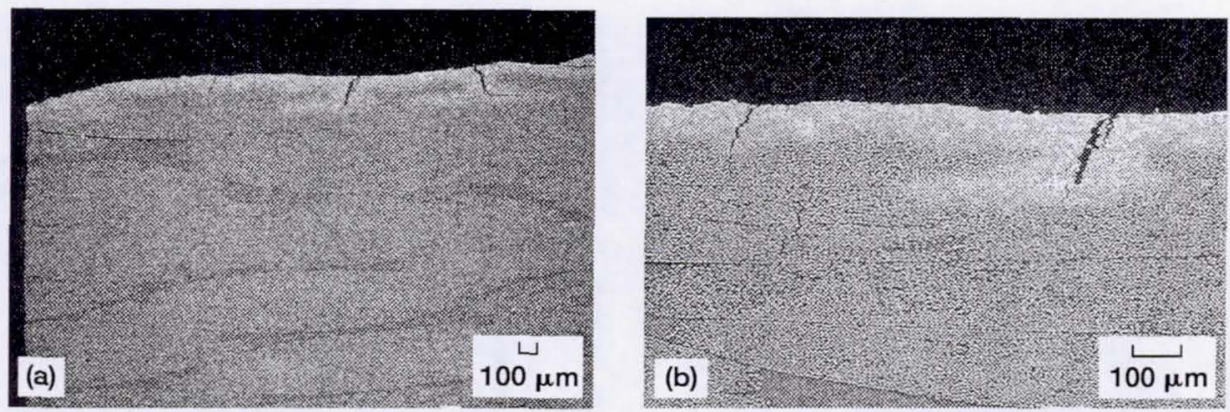

Figure 12.-SEM-BSE picture of oxygen distribution in T650-35/PMR-15 composite. White areas are areas of high oxygen concentration. (a) Magnification is X20.

(b) Magnification is $\mathrm{X} 100$. Composite was aged at $316^{\circ} \mathrm{C}$ for $500 \mathrm{hr}$.
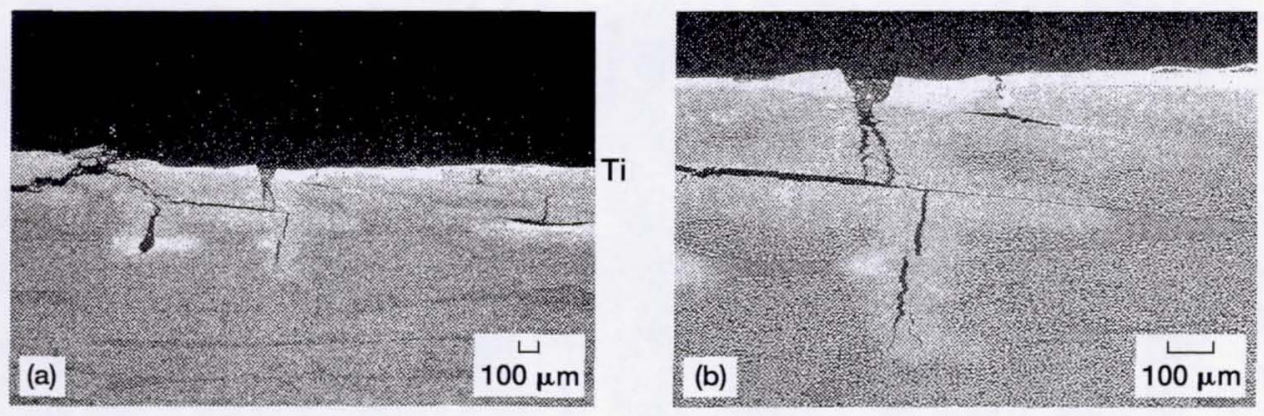

Figure 13.-SEM-BSE picture of oxygen distribution in T650-35/PMR-15 composite. White areas are areas of high oxygen concentration. (a) Magnification is X20.

(b) Magnification is $\mathrm{X} 100$. Composite was aged at $316^{\circ} \mathrm{C}$ for $1000 \mathrm{hr}$.
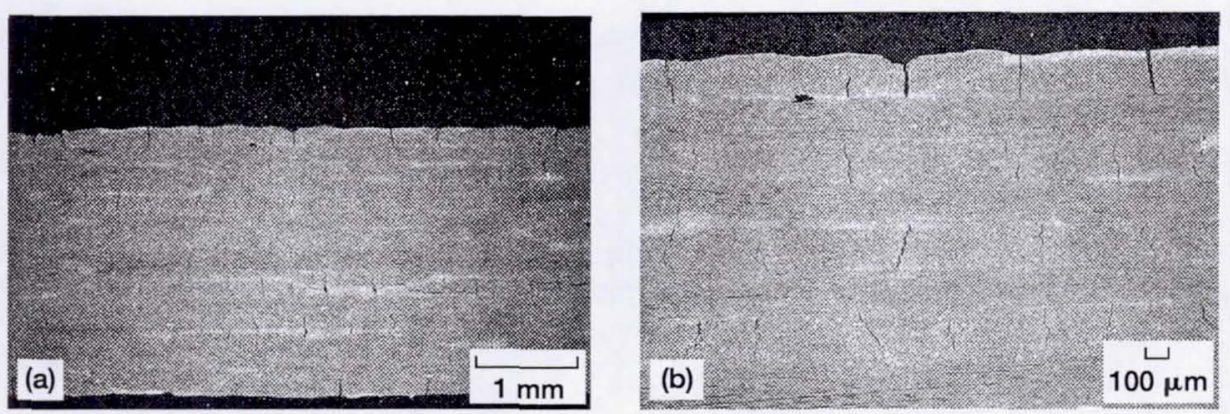

Figure 14.-SEM-BSE picture of oxygen distribution in T650-35 fabric/PMR-15 composite. White areas are areas of high oxygen concentration. (a) Magnification is $\mathrm{X} 20$. (b) Magnification is X100. Composite was aged at $204^{\circ} \mathrm{C}$ for $10000 \mathrm{hr}$. 

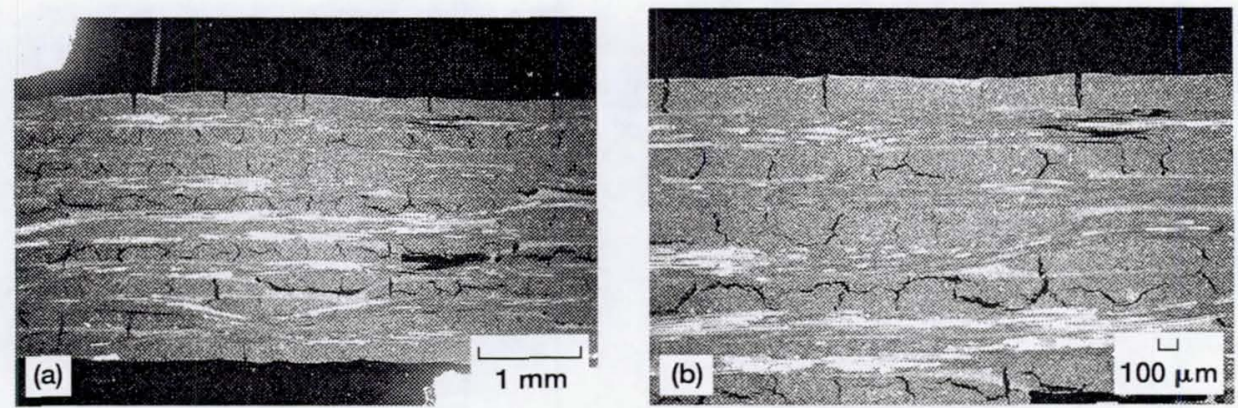

Figure 15.-SEM-BSE pictures of oxygen distribution in T650-35 fabric/PMR-15 composite. White areas are areas of high oxygen concentration. (a) Magnification is X20. (b) Magnification is X100. Composite was aged at $260{ }^{\circ} \mathrm{C}$ for $10000 \mathrm{hr}$.

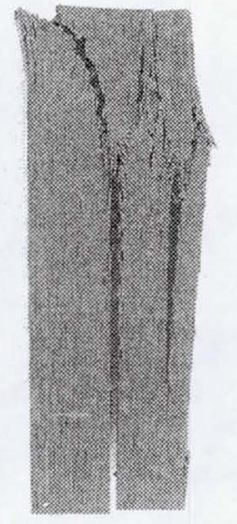

Figure 16.-T-50 specimen after compression test. Wedge formed at the top.

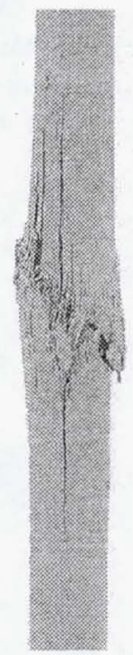

Figure 17.-Compression failure in the gage section of $\mathrm{T}-12$ specimen.

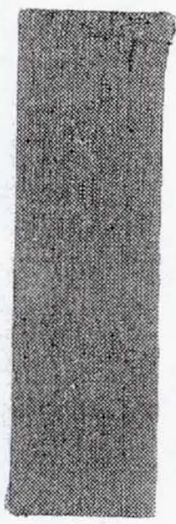

Figure 18.-Compression end failure of a T-50 specimen. Failed surface has "broomed" out at the upper surface of the specimen. 
Public reporting burden for this collection of information is estimated to average 1 hour per response, including the time for reviewing instructions, searching existing data sources, gathering and maintaining the data needed, and completing and reviewing the collection of information. Send comments regarding this burden estimate or any other aspect of this Davis Highway, Suite 1204, Arlington, VA 22202-4302, and to the Office of Management and Budget, Paperwork Reduction Project (0704-0188), Washington, DC 20503.

\begin{tabular}{|l|l|l|}
\hline 1. AGENCY USE ONLY (Leave blank) & $\begin{array}{c}\text { 2. REPORT DATE } \\
\text { March } 1996\end{array}$ & $\begin{array}{r}\text { 3. REPORT TYPE AND DATES COVERED } \\
\text { Technical Memorandum }\end{array}$ \\
\hline
\end{tabular}

\section{TITLE AND SUBTITLE}

Long-Term Isothermal Aging Effects on Carbon Fabric-Reinforced PRM-15

Composites: Compression Strength

\section{6. $\operatorname{AUTHOR}(\mathrm{S})$}

Kenneth J. Bowles, Gary D. Roberts, and John E. Kamvouris
5. FUNDING NUMBERS

WU-505-63-12

\section{PERFORMING ORGANIZATION NAME(S) AND ADDRESS(ES)}

National Aeronautics and Space Administration

Lewis Research Center

Cleveland, Ohio 44135-3191
8. PERFORMING ORGANIZATION REPORT NUMBER

E-9947
9. SPONSORING/MONITORING AGENCY NAME(S) AND ADDRESS(ES)

National Aeronautics and Space Administration

Washington, D.C. 20546-0001
10. SPONSORING/MONITORING AGENCY REPORT NUMBER

NASA TM-107129

\section{SUPPLEMENTARY NOTES}

Prepared for the Second Symposium on High Temperature and Environmental Effects on Polymeric Composites sponsored by the American Society for Testing and Materials, Norfolk, Virginia, November 13, 1995. Kenneth J. Bowles and Gary Roberts, NASA Lewis Research Center; John Kamvouris, National Research Council-NASA Research Associate at Lewis Research Center. Responsible person, Kenneth J. Bowles, organization code 5150, (216) 433-3197.

12a. DISTRIBUTION/AVAILABILITY STATEMENT 12b. DISTRIBUTION CODE

Unclassified - Unlimited

Subject Category 24

This publication is available from the NASA Center for Aerospace Information, (301) 621-0390.

\section{ABSTRACT (Maximum 200 words)}

A study was conducted to determine the effects of long-term isothermal thermo-oxidative aging on the compressive properties of T-650-35 fabric reinforced PMR-15 composites. The temperatures that were studied were 204, 260, 288, 316 , and $343{ }^{\circ} \mathrm{C}$. Specimens of different geometries were evaluated. Cut edge-to-surface ratios of 0.03 to 0.89 were fabricated and aged. Aging times extended to a period in excess of 15000 hours for the lower temperature runs. The unaged and aged specimens were tested in compression in accordance with ASTM D-695. Both thin and thick (plasma) specimens were tested. Three specimens were tested at each time/temperature/geometry condition. The failure modes appeared to be initiated by fiber kinking with longitudinal, interlaminar splitting. In general, it appears that the thermooxidative degradation of the compression strength of the composite material may occur by both thermal (time-dependent) and oxidative (weight-loss) mechanisms. Both mechanisms appear to be specimen-thickness dependent.

\begin{tabular}{|c|c|c|}
\hline $\begin{array}{l}\text { 14. SUBJECT TERMS } \\
\text { Composites; Polymer ma } \\
\text { Thermal aging }\end{array}$ & ix, Carbon fiber; Durability; & oression properties; \\
\hline $\begin{array}{l}\text { 17. SECURITY CLASSIFICATION } \\
\text { OF REPORT }\end{array}$ & $\begin{array}{l}\text { 18. SECURITY CLASSIFICATION } \\
\text { OF THIS PAGE }\end{array}$ & $\begin{array}{l}\text { 19. SECURITY CLASSIFICATION } \\
\text { OF ABSTRACT }\end{array}$ \\
\hline Unclassified & Unclassified & Unclassified \\
\hline
\end{tabular}

